\title{
Arduino Based Turkey Egg Incubator With Molen Rotation Method
}

\section{Alat Penetas Telur Kalkun Berbasis Arduino Dengan Metode Putaran Molen}

\author{
Ardi Prayugo', Syamsudduha Syahrorini. ${ }^{2}$ \\ \{prayugoardi76@gmail.com,syahrorini@umsida.ac.id\}
}

Program Studi Teknik Elektro, Fakultas Sains dan teknologi, Universitas Muhammadiyah Sidoarjo

\begin{abstract}
Today's modern world of hatching many turkey eggs uses various incubators. Arduino-based turkey egg incubator with the molen rotation method uses an Arduino microcontroller that is connected to a DHT11 sensor for turkey egg incubator using the molen rotation method. Temperature and humidity are the main factors to determine the success at hatching of eggs, but also the need for the fertilization process in the eggs to be hatched because fertilization also determines the success rate at hatching eggs. Testing of the incubator is carried out directly from the turkey egg incubator at the temperature in the room and rotates it with the automatic spinning method with an angle of $360^{\circ}$ every 4 hours. DHT11 can detect temperature and humidity in the incubator room, the optimal temperature for hatching turkey eggs is $37^{\circ}-38^{\circ} \mathrm{C}$ and the optimal humidity is $55-60 \% \mathrm{RH}$, and the servo motor is able to move to move the egg rack according to the time specified. The measurement results of the DHT11 sensor readings are as desired with a minimum temperature reading of $37^{\circ} \mathrm{C}$ and a maximum temperature of $39^{\circ} \mathrm{C}$ with humidity that has been set at 55-60\% and the molen rotation method runs according to the desired time every 6 hours for 4 times with $360^{\circ}$ rotation, at days 1-26 turkey eggs hatch with a result of 3: 2 in the sense that 3 successfully hatched and 2 failed to hatch.
\end{abstract}

Key words: Arduino; DHT11 sensor; egg turning rack; RTC DS3231

\begin{abstract}
Abstrak. Dunia modern saat ini penetasan telur kalkun banyak menggunakan mesin penetas berbagai madel. Penetas telur kalkun berbasis arduino dengan metode putaran molen ini menggunakan mikrokontroller Arduino yang terhubung dengan sensor DHT11 untuk mesin penetas telur kalkun dengan metode putaran molen. Suhu dan kelembaban adalah faktor utama untuk menentukan keberhasilan saat penetasan telur, namun juga perlunya proses fertilasi pada telur yang akan ditetaskan karena dari fertilasilah juga menentukan tingkat keberhasilan saat penetasan telur. Pengujian alat penetas dilakukan secara langsung dari alat penetas telur kalkun dengan suhu yang ada didalam ruangan dan melakukan pemutaran dengan metode putaran molen secara otomatis dengan sudut $360^{\circ}$ setiap 4 jam sekali. DHT11 dapat mendeteksi suhu dan kelembaban dalam ruangan alat penetas, temperatur optiomal penetasan telur kalkun $37^{\circ}-38^{\circ} \mathrm{C}$ dan kelembaban optimal 55-60\% RH, dan motor servo mampu bergerak untuk menggerakan rak telur sesuai waktu yang ditentukan. Hasil pengukuran pembacaan sensor DHT11 sesuai dengan yang diinginkan dengan pembacaan suhu minimal $37^{\circ} \mathrm{C}$ dan suhu maksimalnya $39{ }^{\circ} \mathrm{C}$ dengan kelembaban yang telah di setting 55$60 \%$ dan metode putaran molennya berjalan sesuai waktu yang di inginkan setiap 6 jam sekali selama 4 kali dengan putaran 360", pada hari 1-26 telur kalkun menetas dengan hasil 3:2 dalam arti 3 berhasil menetas dan 2 gagal menetas.
\end{abstract}

Kata kunci : Arduino; Sensor DHT11; Rak pemutar telur; DS3231

\section{PENDAHULUAN}

Alat penetas telur adalah sebuah alat untuk membantu proses penetasan telur. Dengan adanya alat penetas telur ini sehingga tidak memerlukan indukan untuk membantu proses pengeraman. Prinsipnya penetasan telur harus sesuai dengan proses pengeraman oleh indukan yang secara alami sehingga embiro dapat berkembang dengan baik sehingga telur dapat menetas dengan maksimal. Ada beberapa hal yang harus diperhatikaan pada penetasan telur yaitu suhu dan kelembaban, putaran pada rak telur, kebersihan pada telur kalkun[1]. Embiro pada telur kalkun akan berkembang selama suhu telur berada pada kondisi yang sesuai dan akan berhenti berkembang jika suhu tidak stabil. Suhu yang dibutuhkan untuk penetasan telur kalkun sekitar $37^{\circ} \mathrm{C}-38^{\circ} \mathrm{C}[1][2]$. kestabilan suhu sangat penting untukpenetasan telur kalkun. maka dari itu dibutuhkan suhu yang stabil untuk penetasan telur kalkun [1][3]. Sedangkan untuk kelembaban pada alat penetas telur kalkun juga sangat penting untuk pertumbuhan embiro pada telur kalkun, kelembaban pada alat penetas telur kalkun sekitar 55-60\% [3][4].

Alat penetas telur kalkun dengan metode putaran molen ini bertujuan untuk menetaskan telur kalkun dengan hasil yang maksimal, suhu dan kelembaban ditampilkan pada LCD, arduino UNO, sensor DHT11, sensor water level, serta RTC DS3231 sebagai kontroller [5][6][7]. 


\section{METODOLOGI PENELITIAN}

Pada penelitian ini alat penetas telur kalkun dengan metode putaran molen berbasis arduino,selanjutnya di lakukan uji coba selama 28 hari.

Dalam alat penetas telur kalkun dengan metode putaran molen berbasis arduino memakai komponen: arduino, sensor DHT11, RTC DS3231, relay 4 chanel, kipas,motor AC.

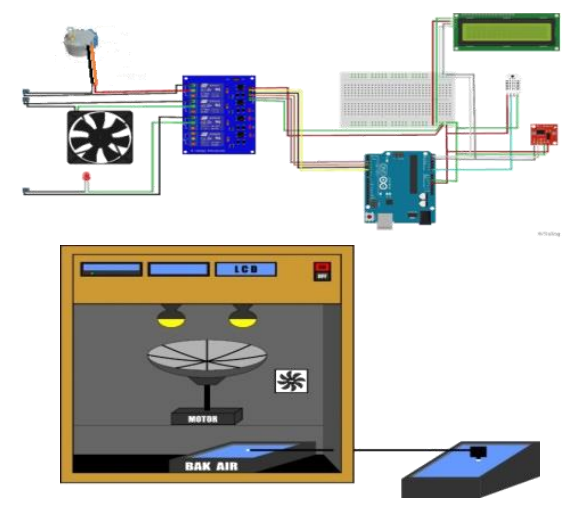

Gambar 1. Desain alat

LCD sebagai pemantau suhu dan kelembaban , 2 buah lampu sebagai pemenas telur , rak pemuta telur, kipas blower, bak ber isi air dengan pompa .pengujian gambar diatas ditunjukan pada tabel dibawah ini.

\section{HASIL DAN PEMBHASAN}

Tabel 1. Hasil pengujian sensor suhu DHT11

\begin{tabular}{|c|c|c|c|c|c|c|c|c|}
\hline \multirow[b]{2}{*}{ waktu } & \multirow[b]{2}{*}{$\begin{array}{l}\text { Ther } \\
\text { mome } \\
\text { ter }{ }^{\circ} \mathrm{C}\end{array}$} & \multirow[b]{2}{*}{$\begin{array}{l}\mathrm{R} \\
\mathrm{H} \\
\%\end{array}$} & \multicolumn{2}{|c|}{ DHT 11} & \multirow[b]{2}{*}{$\begin{array}{c}\text { Akura } \\
\text { si } \\
(\%)\end{array}$} & \multirow[b]{2}{*}{$\begin{array}{c}\text { Erro } \\
r \\
(\%)\end{array}$} & \multicolumn{2}{|c|}{ Standart Deviasi } \\
\hline & & & ${ }^{\circ} \mathrm{C}$ & $\%$ & & & $\begin{array}{c}\text { Thermost } \\
\text { at } \\
\left({ }^{\circ} \mathrm{C}\right)\end{array}$ & $\begin{array}{l}\text { Sens } \\
\text { or } \\
\left({ }^{\circ} \mathrm{C}\right) \\
\end{array}$ \\
\hline 06.00 & 39,3 & 64 & 38,3 & 57 & 97,39 & 2,61 & & \\
\hline 12.00 & 37,8 & 64 & 38,3 & 57 & 98,7 & 1,3 & & \\
\hline 18.00 & 37,5 & 63 & 38,0 & 59 & 97,39 & 1,31 & & \\
\hline 23.59 & 38,6 & 62 & 38,8 & 56 & 99,49 & 0,51 & 0,833 & $\begin{array}{c}0,33 \\
8\end{array}$ \\
\hline 06.00 & 37,3 & 65 & 37,9 & 60 & 98,42 & 1,58 & & \\
\hline $\begin{array}{l}\text { Rata- } \\
\text { rata }\end{array}$ & 38,1 & & $\begin{array}{c}38,2 \\
6\end{array}$ & & & & & \\
\hline
\end{tabular}

Tabel 1 menunjukkan hasil pengukuran suhu dari sensor DHT11 yang dilakukan pada mesin penetas. Pengukuran suhu tersebut dilakukan pada saat proses selama masa penetasan telur. Dari hasil percobaan didapatkan data dengan nilai suhu paling kecil sebesar $37^{\circ} \mathrm{C}$ dan nilai suhu paling besar sebesar $39^{\circ} \mathrm{C}$ dengan Error atau kesalahan paling kecil 0,51\% dan paling besar 2,61\%. Sedangkan nilai Standart Deviasi pada hasil percobaan menggunakan sensor DHT11 sebesar 0,338 serta nilai Standart Deviasi pada hasil percobaan menggunakan Thermostat Digital sebesar 0,833. Beberapa data tersebut dapat dilihat pada Tabel 4.1 di atas. Hasil nilai Standart Deviasi pada sensor 
Procedia of Engineering and Life Science Vol. 1. No. 2 Juni 2021

Seminar Nasional \& Call Paper Fakultas Sains dan Teknologi (SENASAINS 2nd)

Universitas Muhammadiyah Sidoarjo

DHT11,Thermostat Digital,Hygrometer hampir sama, sehingga dapat disimpulkan bahwa sensor DHT11 tersebut dapat bekerja dan berfungsi dengan baik[8][9].

Tabel 2. Pengujian Motor Stepper

\begin{tabular}{cccc}
\hline No & waktu & $\begin{array}{c}\text { Kondisi } \\
\text { input }\end{array}$ & Kondisi motor \\
\hline 1 & 06.00 & High & On \\
2 & 06.06 & Low & Off \\
3 & 12.00 & High & On \\
4 & 12.06 & Low & Off \\
5 & 18.00 & High & On \\
6 & 18.06 & Low & Off \\
7 & 23.59 & High & On \\
8 & 23.05 & Low & Off \\
\hline
\end{tabular}

Tabel 2 menunjukkan hasil pemutaran motor stepper dengan waktu yang telah di tentukan. Dari hasil percobaan didapatkan data yang sesuai dengan yang di harapkan. Berdasarkan data dari hasil pengujian tersebut, maka dapat diketahui bahwa motor stepper dapat berjalan dengan baik, dimana motor stepper berjalan sesuai waktu yang ditentukan.

Tabel 3. pengujian RPM rak telur selama 360 menit tanpa beban telur kalkun.

\begin{tabular}{lllll}
\hline No & Waktu & RPM & Suhu & kelembaban \\
\hline 1 & 60 & 69,2 & 37,5 & $59 \%$ \\
2 & 60 & 68,4 & 37,4 & $57 \%$ \\
3 & 60 & 68,7 & 37,9 & $60 \%$ \\
4 & 60 & 68,5 & 38,1 & $59 \%$ \\
5 & 60 & 68,8 & 37,8 & $57 \%$ \\
6 & 60 & 68,6 & 38,4 & $58 \%$ \\
\hline
\end{tabular}

Tabel 4. pengujian RPM rak telur selama 360 menit menggunakan beban 5 telur kalkun.

\begin{tabular}{lcccc}
\hline No & Waktu & RPM & Suhu & kelembaban \\
\hline 1 & 60 & 57,6 & 37,1 & $60 \%$ \\
2 & 60 & 58,3 & 37,5 & $59 \%$ \\
3 & 60 & 57,6 & 38,3 & $60 \%$ \\
4 & 60 & 60,1 & 38,4 & $57 \%$ \\
5 & 60 & 59,3 & 38,1 & $59 \%$ \\
6 & 60 & 60,1 & 37,8 & $58 \%$ \\
\hline
\end{tabular}

Dari tabel 3 dapat disimpulkan bahwa hasil pengukuran selama 1 hari RPM tanpa menggunakan beban telur yaitu 1.648,8 RPM sedangkan dari tabel 4 yang menggunakan beban 5 buah telur kalkun yaitu 1.412 RPM. 
Procedia of Engineering and Life Science Vol. 1. No. 2 Juni 2021

Seminar Nasional \& Call Paper Fakultas Sains dan Teknologi (SENASAINS 2 ${ }^{\text {nd }}$ )

Universitas Muhammadiyah Sidoarjo

Tabel 5. Pengujian Alat Penetas Telur

\begin{tabular}{|c|c|c|c|c|}
\hline No & $\begin{array}{c}\text { Minggu } \\
\mathrm{ke}\end{array}$ & penjelasan & Hasil / Gambar & Keterangan \\
\hline 1 & 1 & $\begin{array}{l}\text { Pada hari } \\
\text { ke } 1 \text { belum } \\
\text { terbentuk } \\
\text { embrio }\end{array}$ & $E$ & $\begin{array}{l}\text { Pada hari 1-3 } \\
\text { telur tidak } \\
\text { boleh } \\
\text { digerakan dan } \\
\text { suhu } 37-39^{\circ} \mathrm{C} \\
\text { kelembaban } \\
55-60 \%\end{array}$ \\
\hline 2 & 2 & $\begin{array}{c}\text { Di minggu } \\
\text { ke } 7 \text { dapat } \\
\text { dilihat } \\
\text { embrio } \\
\text { sudah } \\
\text { nampak }\end{array}$ & & $\begin{array}{c}\text { Pada hari ke } \\
\text { 4-7 telur sudah } \\
\text { mulai bisa } \\
\text { dibolak balik } \\
\text { dengan putaran } \\
\text { molen yaitu } \\
360^{\circ} \text { atau satu } \\
\text { putaran penuh } \\
\text { selama } 30 \\
\text { detik dan suhu } \\
\text { nya tetap stabil } \\
\text { kisaran } 37-39^{\circ} \\
\text { C dan } \\
\text { kelembabanya } \\
55-60 \% \\
\end{array}$ \\
\hline 3 & - & $\begin{array}{c}\text { Di usia } 19 \\
\text { hari rongga } \\
\text { telur sudah } \\
\text { terisi full } \\
\text { dan sudah } \\
\text { berbentuk } \\
\text { ayam } \\
\text { kalkun } \\
\text { tinggal } \\
\text { menunggu } \\
\text { waktu } \\
\text { menetas }\end{array}$ & & $\begin{array}{c}\text { Pada umur } 19 \\
\text { hari } \\
\text { kelembaban } \\
\text { telur sekitar } \\
55-65 \% \text { dan } \\
\text { suhu telurnya } \\
\text { tetap harus } \\
\text { normal sekitar } \\
\text { 37-39 }{ }^{\circ} \mathrm{C} \\
\text { supaya } \\
\text { penetasan } \\
\text { berhasil dan } \\
\text { pembalikan } \\
\text { telur harus di } \\
\text { hentikan } \\
\text { karena telur } \\
\text { sudah mulai } \\
\text { mencari posisi } \\
\text { untuk } \\
\text { persiapan } \\
\text { menetas }\end{array}$ \\
\hline 4 & - & $\begin{array}{c}\text { Umur } 26 \\
\text { sudah } \\
\text { mulai } \\
\text { keluar dari } \\
\text { cangkakng } \\
\text { telurnya }\end{array}$ & & $\begin{array}{l}\text { Pada umur } 26 \\
\text { hari telur } \\
\text { sudah mulai } \\
\text { retak dan } \\
\text { tinggal } \\
\text { menunggu } \\
\text { waktu nya } \\
\text { suhu nya tetap } \\
\text { stabil kisaran } \\
37-39^{\circ} \mathrm{C} \text { dan } \\
\text { posisi telur } \\
\text { tidak perlu di }\end{array}$ \\
\hline
\end{tabular}




\begin{tabular}{|l|l|l|l|c|}
\hline & & & $\begin{array}{c}\text { bolak balik } \\
\text { lagi }\end{array}$ \\
\hline
\end{tabular}

Tabel 5 menunjukkan hasil dari dari proses selama penetasan berlangung yang dilakukan pada mesin penetas telur kalkun dengan metode putaran molen. Pengujian dilakukan dengan memasukan telur kalkun berjumlah 5 kedalam alat hingga waktu penetasan berlangsung. Telur kalkun didapatkan langsung dari kandang indukan ayam kalkun. Telur yang dapat ditetaskan yang kurang dari 7 hari karena jika melebihi 7 hari embrio tidak dapat berkembang atau mati. Selama proses penetasan harus dilakukan pengecekan pertumbuhan embrio pada telur dengan cara mengambil telur dan diterawang menggunakan flash handphone ditempat yang minim cahaya supaya dapat dengan jelas saat peneropongan. Pengukuran suhu dan kelembaban tersebut dilakukan pada mesin penetas dalam beberapa percobaan. Dari hasil percobaan didapatkan data dengan nilai suhu paling kecil sebesar $37.00^{\circ} \mathrm{C}$ dan nilai suhu paling besar sebesar $39.00^{\circ} \mathrm{C}$. Sedangkan kelembabanya 55\%-60\%[10].

Pada hari pertama telur nampak masih polos cerah dan belum ada embrio yang berkembang di dalam telur.

Pada hari ketujuh telur sudah mulai terlihat perkembangannya yang dapat dilihat pada gambar 4.5, terbentuknya benih embrio akan terlihat seperti benang darah berwarna merah yang memanjang dan terlihat juga gumpalan embrio.

Pada hari ke 19 hari telur kalkun sudah terisi dan sudah menjadi bentuk ayam kalkun sampai menunggu waktunya menetas.

Pada hari ke 26 telur sudah mulai meretakan cangkang telurnya.Dihari ke27 kalkun sudah mulai keluar dari cangkangnya, jika ayam kalkun sudah berhasil keluar dari cangkangnya tunggu cairan yang ada di badan ayam mengering lalu pindahkan ke tempat yang disinari lampu supaya kehangatan ayam kalkun terjaga.

Tingkat keberhasilan mesin penetas dengan metode putaran molen ini bisa dibilang berhasil karena dari ke 5 telur yang di tetaskan ada 2 yang tidak dapat menetas dan ada 3 yang berhasil menetas tetapi ada 1 yang menetas tidak sempurnah. Dari gagalnya kedua telur yang tidak menetas karena pemilihan telur yang kurang baik atau telurnya sudah lebih dari 7 hari.

\section{KESIMPULAN}

Berdasarkan alat penetas telur kalkun dengan metode putaran molen dapat disimpulkan sebagai berikut: Alat penetas telur kalkun dengan metode putaran molen berbasis arduino bekerja sesuai yang diharapkan. Terbukti dengan sensor yang mendeteksi suhu dan kelembaban dan dapat mengirim data yang selanjutnya akan ditampilkan pada LCD. Untuk sensor suhu dan kelembaban meski hasil output pengukuran memiliki selisih dengan thermostat dan hygrometer namun tidak terlalu signifikan dan alat ini tetap bekerja sesuai harapan yaitu tidak lebih dari $37^{\circ} \mathrm{C}-39^{\circ} \mathrm{C}$. Prinsip kerja alat ini dengan mengoyang rak telur dengan metode putaran molen dan dapat mengendalikan suhu dan kelembaban pada mesin penetas yang di proses oleh sensor DHT11 dan selanjutnya ditampilkan pada LCD.

\section{DAFTAR PUSTAKA}

[1] R. H. Rahim, "Rancang Bangun Alat Penetas Telur Otomatis Berbasis Mikrokontroler ATMega8535," E-Journal Tek. Elektro Dan Komput., vol. 4, no. 1, pp. 1-7, 2015.

[2] R. Chen, W. Zhai, and Y. Qi, "Mechanism and technique of friction control by applying electric voltage. (II) Effects of applied voltage on friction," Mocaxue Xuebao/Tribology, vol. 16, no. 3, pp. 235-238, 1996.

[3] I. Rizki, K. Kustanto, and S. Siswanti, "Sistem Monitoring Pengontrol Suhu Dan Intensitas Cahaya Pada Penetas Telur Puyuh," J. Teknol. Inf. dan Komun., vol. 6, no. 1, 2018.

[4] R. Wahyudi, "Pembuatan mesin penetas telur otomatis," 2017.

[5] F. Nurpandi and A. P. Sanjaya, "Inkubator Penetasan Telur Ayam Berbasis Arduino," Media J. Inform., vol. 9, no. 2, pp. 66-77, 2018.

[6] A. N. Putra, "Sistem Otomasi Pengering Pakaian Berbasis Mikrokontroller Arduino," J. SAINTEK, vol. 13, no. 2, p. 70, 2016.

[7] A. B. Laksono and A. Bachri, "Rancang Bangun Otomatisasi Mesin Penetas Telur Sistem Turning Berbasis Mikrokontroler Atmega 328," J. Progr. Stud. Tek. Elektro JE-Unisla Ranc., pp. 6-9, 2017.

[8] C. C. Ratag, "Penetas Telur Berbasis Mikrokontroler At89C52," J. Teknol. Inf., vol. VII, pp. 125-136, 2013.

[9] S. Syahrorini and D. Hadidjaja, “Aplikasi Alat Ukur Partikulat Dan Suhu Berbasis Iot,” Dinamik, vol. 25, no. 1, pp. 1-9, 2020.

[10] F. Ahyodi, K. Nova, and T. Kurtini, "Pengaruh Bobot Telur terhadap Fertilitas, Susut Tetas, Daya Tetas, dan Bobot Tetas Telur Kalkun,” Jipt, vol. 2, no. 1, pp. 19-25, 2014.

[8] S. S. Rui SAntos, 18+ arduino Project, Microsoft@word 2013, 2018.

[9] Prawoto,I.(2015). Pengertian arduino uno mikrokontroler atmega328. Diambil pada 19 Juli 2019 dari https://www.caratekno.com/2015/07/pengertian-arduino-unomikrokontroler.html

[10] Rahim, R. H. (2015). Rancang Bangun Alat Penetas Telur Otomatis berbasis Mikrokontroler ATMega8535. EJournal Teknik Elektro Dan Komputer, 4(1), 1-7. 